\title{
Collaborative Identification and Prioritisation of Mental Health Nursing Care Process Metrics and Indicators: A Delphi Consensus Study
}

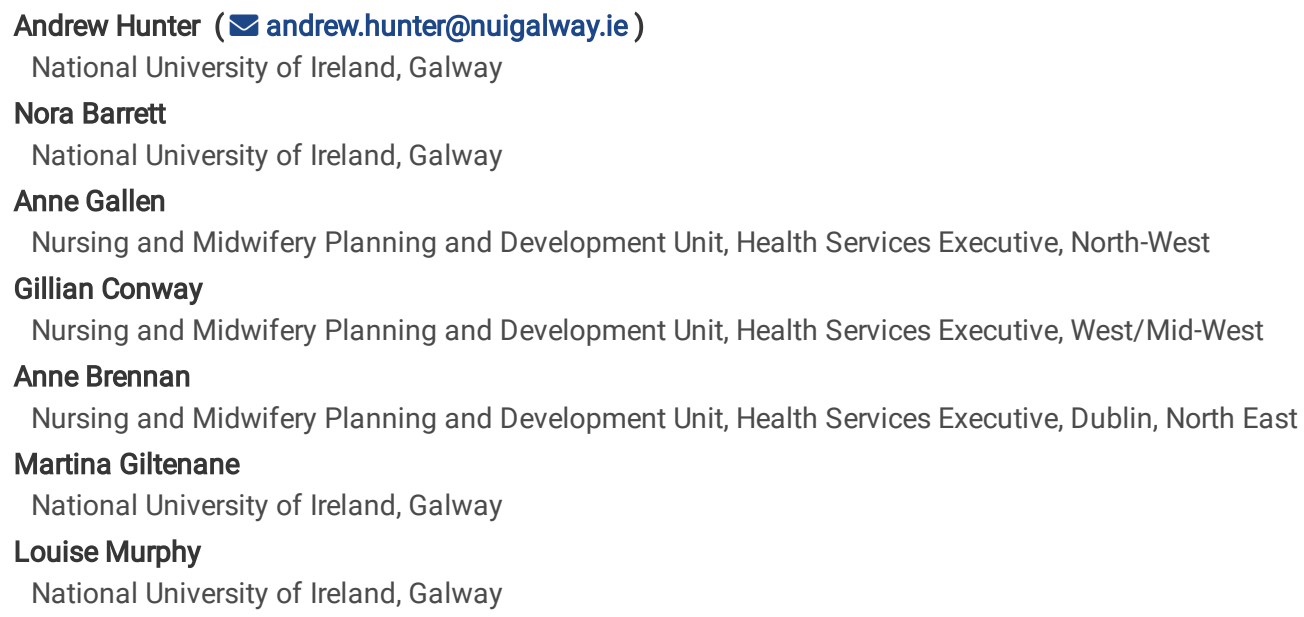

\section{Research Article}

Keywords: Quality care metrics, Mental Health Nursing care processes, Delphi survey

Posted Date: June 7th, 2021

DOI: https://doi.org/10.21203/rs.3.rs-524546/v1

License: (a) (1) This work is licensed under a Creative Commons Attribution 4.0 International License. Read Full License

Version of Record: A version of this preprint was published at BMC Health Services Research on March 16th, 2022. See the published version at https://doi.org/10.1186/s12913-022-07659-2. 


\section{Abstract \\ Background}

The Irish Office of Nursing \& Midwifery Services Director (ONMSD) commissioned the development an updated suite of mental health nursing metrics and indicators for implementation in Irish mental health clinical settings. While measuring care processes does offer the potential to improve care quality, the choice of which mental health nursing metrics to measure presents a significant challenge, both in Ireland and internationally. The provision of safe and high-quality mental health nursing care stems from nurses' expertise, skills and overall capacity to provide recovery focused care across a range of health care settings. Accordingly, efforts to measure what mental health nurses do depends on the identification of those care processes that contribute to mental health nursing practice. This paper reports on the identification, development and prioritisation of a national suite of Quality Care Metrics (QCM), along with their associated indicators, for mental health nursing care processes in Ireland.

\section{Methods}

The study was undertaken over four phases; i) a systematic literature review to identify mental health care process metrics and their associated indicators of measurement; ii) a two-round, online Delphi survey of mental health nurses to develop consensus on the suit of mental health nursing care process metrics; iii) a two-round online Delphi survey of mental health nurses to develop consensus on the indicators to be used to measure the agreed metrics; and iv) a face-to-face consensus meeting with mental health nurses and service user representatives to develop consensus on the final suite of metrics and indicators.

\section{Results}

Following these four phases 9 metrics and their 73 associated indicators were agreed for inclusion in the final suite of Mental Health Nursing QCM. These metrics are applicable across the life span and the range of mental health nursing health care settings.

\section{Conclusion}

The development of this suite of Mental Health Nursing QCM and their indicators represents an opportunity for the measurement of safe and high-quality mental health nursing care for application in Ireland and internationally. This initial development of metrics and indicators should be followed by a rigorous baseline review of QCM uptake and implementation amongst mental health nurses as part of an ongoing evaluation.

\section{Background}

The Health Service Executive (HSE) in The Republic of Ireland, along with many other international health care providers recognise the need for high quality, standardised data collection that quantifies nursing and midwifery care processes (Kings Fund 2017; HSE 2014). While such data can contribute to improved understanding of mental health nursing care processes, the choice of which mental health nursing metrics to measure presents a significant challenge in Ireland and internationally (Maben et al 2012).

Contemporary mental health care policy emphasises the need for measurement of the contribution of mental health nurses to patient safety and clinical quality improvement (HSE 2017a; HSE 2016; HSE 2012). Currently in Ireland and internationally there very limited research in this area and as such no quantifiable means of establishing the contribution of mental health nursing processes to the outcomes of people in receipt of mental health nursing care across the lifespan and healthcare settings. Notable historical efforts to identify and quantify what mental health nurses do include the development of clinical indicators for mental health nursing in Australia and New Zealand in the 2000s. While not developing metrics and their associated indicators, Skews et al (2000) and O'Brien et al (2004) produced clinical indicators and endeavoured to audit these as a means of comparing and benchmarking practice across mental health settings. It is noteworthy that these studies acknowledged the challenge of capturing the totality of mental health nursing practice and of embedding such measurement approaches. In a discussion on mental health nursing culture Slemon et al (2017) note that mental health nursing practice remains focused on mitigating risk and promoting safety, while lacking effective structures. Indeed, even in these priority areas, where mental health nurses utilise rigorous monitoring and recording as means of risk management the evidence is that current approaches lack efficacy (De Santis et al., 2015).

In response to the identified need the Office of Nursing and Midwifery Services Directorate in Ireland commissioned a national research study to establish a consensus on how nursing and midwifery care processes that should be measured (HSE 2018a). This national study aimed to develop care process metrics and indicators that where possible would align with evidenced-based clinical practice guidelines and standards. This study produced a suite of seven QCM reports that outline these metrics and associated indicators in the healthcare areas of Mental Health, Midwifery, Children's Community/Public Health, Acute, Older and Intellectual Disability (HSE 2018b). This paper reports the development and prioritisation of a national suite of QCM, and their associated indicators, for mental health nursing in Ireland.

\section{Methods}




\section{Overall Design}

This study comprised four discreet phases outlined below. With all phases overseen by a work stream working group made up of mental health nurses from a range of grades, specialities and geographical areas, service user representation and an academic lead $(n=30)$. The work-stream working group members were invited to participate in the quality care metrics project by letter informing them of the study and inviting them to nominate registered mental health nurses of all grades from their area to participate in the study. The group was provided with regular updates by email and teleconference and met face to face four times over the course of the project; before the Delphi study commenced, during the Delphi study and after the Delphi study had completed, to agree the final suite of metrics.

Phase 1: A systematic literature review to identify mental health nursing metrics that have been used in this area and the indicators for same.

Phase 2: A two-round online Delphi survey of mental health nurses to develop consensus on metrics to be prioritised.

Phase 3: A two-round online Delphi survey of mental health nurses to develop consensus on indicators for the prioritised metrics.

Phase 4: Face-to-face consensus meeting with key stakeholders to review the findings and build consensus on the final suite of metrics and indicators. Ethics:

Ethical approval was granted by the Research Ethics Committee National University of Ireland Galway. All potential participants received a study information sheet, which outlined the purpose of the study, the risks and benefits of participation, confirmed participation was entirely voluntary and the likely time commitment. They were also informed they could ask questions at any point and given contact details to that end. All participants had to explicitly indicate their consent to participate by clicking on the 'I agree' button at the end of the online participant information sheet before accessing the survey. For phase 4, consensus meeting participants were given a participant information leaflet. Written consent to participate was then obtained at the meeting.

\section{Phase 1: Systematic Review}

\section{Systematic review inclusion criteria}

The following inclusion criteria were applied; i) Participants: registered nurses or midwives working in any of the seven identified work-streams, or persons in receipt of nursing or midwifery care from eligible work streams; ii) Exposure: relating to nursing or midwifery quality care processes (metrics or indicators). For the purposes of this study a quality care process metric is defined as a quantifiable measure that captures quality in terms of how (or to what extent) nursing or midwifery care is performed in relation to an agreed standard. A quality care process indicator is defined as a quantifiable measure that captures what nurses or midwives are doing to provide care in relation to a specific tool or method (Foulkes et al 2011); iii) Outcomes: measurable quality process or processes in use or proposed for use; iv) Type of study: any.

\section{Systematic review search strategy}

The literature search was undertaken as a national collaboration across all 7 work streams (Devane et all 2019, Doody et al 2019, Murphy et al 2019.). The aim of the review was to identify quality care process metrics and their associated indicators, and to identify the current evidence base.

Eight databases were systematically searched including: Pubmed, Embase, PyscINFO, ASSIA, Cumulative Index to Nursing and Allied Health Literature (CINAHL), Cochrane Database of Systematic Reviews (CDSR), Cochrane Central Register of Controlled Trials (CENTRAL), and Database of Abstract of Reviews of Effects (DARE).

To maintain contemporary relevance the search was undertaken between 1st January 2007 and 1st January 2017, in English language where full text were available. For this purpose a systematic review procedure was adapted using the search terms nurs*:ab,ti OR midwi*:ab,ti AND ('minimum data set':ab,ti OR indicator*:ab,ti OR metric*:ab,ti OR 'quality measure*':ab,ti) AND [english]/lim AND [2007-2017]/py. The search was not limited to study design but widened to comprise all types of sources including grey literature.

Covidence software (Cochrane 2016) was utilised to manage the retrieved studies. After duplicates were removed, each title was reviewed independently by at least two members of the national academic teams. Disputes were settled by discussion and negotiation. At full text screening, any included studies were tagged to the specific work-streams. Full-text studies relevant to each work-stream were then reviewed by two reviewers (NB and AH for mental health nursing) from the appropriate work-stream. The complete process flow diagram for the systematic literature review is presented in Fig. 1. Search and selection flow diagram.

\section{Systematic Review Findings}

The search conducted across eight databases resulted in 15,304 citations. Following removal of duplicates, 7,524 unique references were identified. Following title and abstract screening, 218 sources were retained, including those identified from hand searching and the grey literature, for full-text screening. Following full text screening, 112 sources were included upon the basis that they met the study's inclusion criteria. These sources were reviewed for reference to mental health nursing care processes and quality processes (see Fig. 1). Eight studies were identified as relevant to mental health nursing. Following screening for quality and content three sources were included for data extraction. Two from the database search (Grabowski, Aschbrenner, Rome, \& Bartels, 2010; Yackel, McKennan, \& Fox-Deise, 2010) both of which referred to measurable approaches to mental health screening,

Page $3 / 11$ 
undertaken by mental health nurses. From the grey literature, the Judgement Support Framework (Mental Health Commission, 2016) a guidance document designed so support quality in mental health care processes implementation and monitoring.

Following the systematic review process, the Mental Health Work Stream Working Group met to discuss the potential metrics extracted from the systematic literature review. At this stage it was agreed that, the pre-existing suite of mental health nursing care process metrics (HSE, 2015) be included in discussion for possible inclusion. Following this discussion, 16 potential mental health nursing metrics were agreed for inclusion in Round 1 of the Delphi survey: 1. Medication Storage and Custody, 2. Management of Controlled Drugs (MDA Drugs), 3. Medication Administration, 4. Ensuring Correct Prescription of Medication, 5. Assessment and Personal Details, 6. Nursing Care Plan, 7. NMBI Record Keeping, 8. Provision of Required Information for Service Users \& Carers, 9. Discharge Planning, 10. Service User Experience, 11. Screening and Evaluation of Mental Health Needs, 12. Use of psychotherapy/nonpharmacological therapeutics i.e. talk therapies, 13. Use of psychiatric medications side effect profile, 14 . Care of the dying, 15.

Communication of Healthcare Team, 16. Therapeutic Communication with service users.

\section{Phase 2 The Delphi Consensus Process}

This stage consisted of a four-round online Delphi survey to develop consensus on prioritised metrics and indicators. At the end of the first two rounds, the metrics were identified and at the end of Round 3 and 4 , the indicators for those metrics were identified.

\section{Sample}

A purposeful convenience sample of mental health nurses working in the mental health services in Ireland were invited to partake in the Delphi survey. Inclusion criteria for the study included any registered mental health nurse working in the HSE mental health services in Ireland, with the ability to give informed consent. Exclusion criteria for the study included any registered mental health nurse not working in the HSE mental health services in Ireland. There were 1102 responses across four Delphi survey rounds.

All mental health nurses who met the inclusion criteria for the study were invited to participate in the study following a comprehensive national advertising campaign via posters, information sheets, word of mouth and presentations at national nursing conferences and events. Participants indicated their interest in the study via email to the research team.

Two, two-round Delphi surveys were conducted, comprising four rounds of data collection and analysis to derive the opinions of participants into group consensus on what metrics (Rounds 1 \& 2) and associated indicators (Rounds 3 \& 4) should be used. Open fields were provided in Rounds 1 and 3 to allow participants to comment on and suggest additional potential metrics and indicators. Responses to each round were collated then redistributed to participants for further comment in successive rounds. Each round had a response closing date of 21 days after the date of invitation. E-mail reminders were sent to anyone who did not respond by day 7 from the date of invitation. Numbers of participants for each round of the Delphi are presented in Table 1.

Table 1

Overall Delphi Responses by Grade and Role

\begin{tabular}{|lllll|}
\hline Grade /Role & Round 1 (n) & Round 2 (n) & Round 3 (n) & Round 4 (n) \\
\hline Staff nurse & 57 & 42 & 41 & 22 \\
\hline Clinical nurse manager (1) & 6 & 3 & 7 & 2 \\
\hline Clinical nurse manager (2) & 76 & 68 & 75 & 47 \\
\hline Clinical nurse manager (3) & 22 & 17 & 14 & 10 \\
\hline Assistant Director of Nursing & 26 & 29 & 27 & 18 \\
\hline Director of Nursing & 1 & 3 & 4 & 3 \\
\hline Community Mental Health Nurse & 33 & 26 & 30 & 18 \\
\hline Nurse Practitioner/Registered Nurse Prescriber & 5 & 5 & 3 & 2 \\
\hline Clinical Nurse Specialist & 0 & 22 & 0 & 0 \\
\hline Clinical Placement Coordinator & 0 & 9 & 0 & 0 \\
\hline Other & 64 & 13 & 60 & 35 \\
\hline Total & $\mathbf{2 9 0}$ & $\mathbf{2 3 7}$ & $\mathbf{2 6 1}$ & $\mathbf{1 5 7}$ \\
\hline
\end{tabular}

Delphi-Round 1: All those who expressed interest in participating were sent email invitations from SurveyMonkey ${ }^{\circledR}$ to participate. A web link was also created as an additional data collector. Round 1 of the Mental Health Metrics Delphi was launched on the 6th of June, 2017 and remained open for 21 Days. The Delphi survey consisted of consent to participate via an: I agree or do not agree button as well as questions regarding demographics.

Participants were asked to rate each of the 16 included metrics from 1-9 (1-Not Important, 9-Very Important). SurveyMonkey ${ }^{\circledR}$ participants were updated weekly according to both Community Health Organisation $(\mathrm{CHO})$ area and nursing grade and circulated to project officers and directors of mental health nursing to track participation rate. Following removal of duplicates and cleaning of responses to include only those who provided an email address, there were a total of 290 participants in Round 1 of the Mental Health Nursing Metrics Delphi survey.

Page $4 / 11$ 


\section{Delphi Round 2}

All who expressed interest and whose responses provided data from Round 1 were sent email invitations via SurveyMonkey ${ }^{\circledR}$ to participate in Round 2 of the Mental Health Metrics Round 2 Delphi. Participants were also sent confidential emails prior to the start of Round 2 with PDF copies of their individual Round 1 survey responses to allow them to re-rate the metrics based on both their responses and the group's responses. Round 2 of the Delphi was launched on the 11th of July 2017 and remained open for 21 Days. Following removal of duplicates there were a total of 233 participants. Round 2 participants were asked to rate 20 proposed metrics that had either been maintained from Round 1, added from open fields in Round 1 of re-worded following review by the work stream working group.

\section{Delphi Round 3}

This round of the Delphi survey was open to new participants that had not previously participated in Round 1 or Round 2 . These participants were asked to rate 80 potential indicators that could be used to measure the seven metrics retained from Rounds 1 and 2 . Email invitations via SurveyMonkey $\AA$ were sent to those who had previously completed Round 1 or Round 2 in addition to any new expressions of interest. Round 3 of the Delphi was launched on the 22 nd of August and remained open for 21 days. Following removal of duplicates there were a total of 283 participants.

\section{Delphi Round 4}

Email invitations for Round 4 of the Delphi survey were only sent to those who provided data in the Round 3 survey. Participants were also sent confidential emails prior to the start of Round 4 with PDF copies of their individual Round 3 survey responses to allow them to re-rate the indicators based on both their responses and the group's responses. Round 4 of the Delphi was launched on the 3rd of October 2017 and remained open for 21 Days.

Following the removal of duplicates there were a total of 143 participants.

\section{Delphi rounds data analysis}

At the completion of Delphi round, round 2 (metrics) and Delphi round 4 (indicators) consensus on inclusion was determined where $70 \%$ or more participants rated the metric or indicator as 7 to 9 and less than $15 \%$ of participants rated the metric as 1 to 3 .

Phase 4: Face-to-face meeting with key stakeholders to build consensus on final metrics and indicators.

This phase comprised of a face-to-face meeting with attending members of the work stream working group $(n=20)$. The work-stream group members were invited to review and build consensus on the quality care process metrics and indicators developed from the Delphi surveys. Participants were provided with a Nursing and Midwifery Judgement Framework Tool adapted from Flenady et al. (2016) to guide their determination on metric/indicator inclusion in the final suite of mental health QCMs (see Table 2).

Table 2

Nursing and Midwifery Judgement Framework Tool

\begin{tabular}{|ll|}
\hline Domain & Description \\
\hline $\begin{array}{l}\text { 1- Process } \\
\text { Focused }\end{array}$ & The metrics/indicator contributes clearly to mental health nursing care processes. \\
\hline 3- Operational & $\begin{array}{l}\text { The data generated by the metric/indicator will likely make an important contribution to improving mental health nursing care } \\
\text { processes. }\end{array}$ \\
\hline 4- Feasible & $\begin{array}{l}\text { Reasured. } \\
\text { It is feasible to collect and report data for the metric/indicator in the relevant setting. }\end{array}$ \\
\hline Modified from: eRegistries indicator evaluation tool (Flenady et al. 2016)
\end{tabular}

Consensus meeting participants voted on each metric and indicator as a yes or no to be included using the Poll Everywhere App. Metrics and indicators were required to receive a vote of $70 \%$ or higher to be included for the final suite in mental health quality care metrics. Follow-up discussions and multiple rounds of voting were used where necessary. Following this process, the final agreed suite of nine mental health nursing process metrics and their indicators were finalised (see Table 3): 


\begin{tabular}{|c|c|}
\hline Metrics $(n=9)$ & Indicators $(n=73)$ \\
\hline \multirow[t]{8}{*}{ Assessment } & Presenting complaints/reasons for admission/attendance is recorded and the admission date and times are recorded \\
\hline & The service user's name, date of birth, and healthcare record number are on each page/screen \\
\hline & Initial assessment includes contact details for family member/carer \\
\hline & There is a documented reason if the service user refuses to give family member/carer details \\
\hline & Documented evidence of discharge planning is recorded from admission \\
\hline & $\begin{array}{l}\text { There is documented evidence of service user consent for family member/carer involvement in care and } \\
\text { communication }\end{array}$ \\
\hline & The service user is involved in all aspects of his/her assessments e.g. falls, risks, neglect etc. as per local policy \\
\hline & $\begin{array}{l}\text { It is documented that the mental health service, with the service user's informed consent has involved other named } \\
\text { service providers in their assessment if required }\end{array}$ \\
\hline \multirow[t]{10}{*}{ Care Plan } & There is documented evidence that the service user is involved in the co-production of their nursing care plan \\
\hline & Nursing interventions are individualised and include nurse's name, signature, the date and time \\
\hline & $\begin{array}{l}\text { There is documented evidence that the nursing care plan has been reviewed on a regular basis, as defined by the } \\
\text { individual clinical area }\end{array}$ \\
\hline & There is documented evidence that information has been provided to the service user on their care and treatment plan \\
\hline & There is documented evidence that the service user is involved in all aspects of his/her treatment and care \\
\hline & Any alterations in nursing documentation are as per NMBI Guidelines \\
\hline & All records are legible, in permanent black ink \\
\hline & Student entries are countersigned by the supervising nurse \\
\hline & All entries are in chronological order \\
\hline & Any abbreviations/grading systems used are from a national or locally approved list/system \\
\hline \multirow[t]{3}{*}{ Management of Risk } & $\begin{array}{l}\text { There is documented evidence that the service user has been systematically assessed for clinical risks by a nurse or } \\
\text { other named professional }\end{array}$ \\
\hline & Where risk is identified there is documentary evidence that a risk management plan is in place \\
\hline & The nursing staff have documented and evaluated the actions taken in a response to any identified clinical risk \\
\hline \multirow{3}{*}{$\begin{array}{l}\text { Management of Violence } \\
\text { and Aggression }\end{array}$} & There is documented evidence that incidents of violence and aggression are recorded \\
\hline & There is documented evidence that timely and appropriate post-incident debriefing has occurred for service users. \\
\hline & There is documented evidence in the nursing care-plan of the nursing responses to violent and/or aggressive incidents \\
\hline \multirow{4}{*}{$\begin{array}{l}\text { Physical Health and } \\
\text { Wellbeing }\end{array}$} & There is documented evidence that that medical history is recorded in the service users' notes \\
\hline & The allergy status is clearly identifiable on nursing documentation \\
\hline & There is documented evidence of an ongoing a physical health assessment from admission/referral. \\
\hline & There is documentary evidence that identified physical health care needs are addressed in the nursing care plan \\
\hline \multirow[t]{4}{*}{ Recovery Based Care } & The service user has been informed of / offered peer support to aid in their recovery \\
\hline & The nurse has documented evidence that the service user has access to a recovery-based programme \\
\hline & $\begin{array}{l}\text { There is documented evidence that the service user is involved in all aspects of his/her recovery planning including } \\
\text { discharge planning }\end{array}$ \\
\hline & $\begin{array}{l}\text { There is documented evidence in the nursing care plan that the nurse has provided Information about voluntary } \\
\text { services that may help service users in their recovery process }\end{array}$ \\
\hline \multirow[t]{4}{*}{ Nursing Communication } & There is evidence in the clinical notes that a nurse has communication with the service user as per care plan \\
\hline & The nurse has offered the service user information regarding their rights \\
\hline & $\begin{array}{l}\text { There is documented evidence in the nursing care plan that the nurse has offered the service user with information on } \\
\text { advocacy services and how to access them }\end{array}$ \\
\hline & There is documented evidence to support the coordination of nursing care on transfer or discharge \\
\hline
\end{tabular}




\begin{tabular}{|c|c|}
\hline \multirow[t]{2}{*}{ Metrics $(n=9)$} & Indicators $(n=73)$ \\
\hline & $\begin{array}{l}\text { There is documented evidence that the service user's communication style and preferences are recorded in the nursing } \\
\text { notes }\end{array}$ \\
\hline \multirow[t]{22}{*}{ Medication Management } & There is documented evidence in the nursing care plan that medication side effects are assessed by the nurse \\
\hline & A registered nurse is in possession of the keys for Medicinal Product Storage \\
\hline & All medicinal products are stored in a locked cupboard or locked room \\
\hline & $\begin{array}{l}\text { All medication trolleys are locked and secured as per local organisational policy and open shelves on the medication } \\
\text { trolley are free of medicinal products when not in use }\end{array}$ \\
\hline & A current drug formulary is available on all medication trolleys \\
\hline & $\begin{array}{l}\text { Misuse Drug Act (MDA) drugs are checked \& signed at each changeover of shifts by nursing staff (member of day } \\
\text { staff \& night staff) }\end{array}$ \\
\hline & Two signatures are entered in the MDA drug register for each administration of an MDA drug \\
\hline & The MDA drug cupboard is locked and keys for MDA cupboard are held by designated nurse \\
\hline & MDA drug keys are kept separate from the other medication keys \\
\hline & $\begin{array}{l}\text { The individual's prescription documentation provides details of individual's legible name and health care record } \\
\text { number }\end{array}$ \\
\hline & $\begin{array}{l}\text { The Individuals' identification band has correct and legible name and healthcare record number and/or photo ID if in } \\
\text { use }\end{array}$ \\
\hline & The allergy status is clearly identifiable on the front page of the prescription chart \\
\hline & Prescribed medicines not administered have an omission code entered \\
\hline & The generic name is used for each drug prescribed \\
\hline & The date of commencement of the most recent prescription is recorded \\
\hline & The prescription is written in block letters \\
\hline & The correct legible dose of the medicine is recorded with correct use of abbreviations \\
\hline & The route and/or site of administration is recorded \\
\hline & The frequency of medicines administration is recorded and correct timings indicated \\
\hline & The minimum dose interval and/or 24 hour maximum dose is specified for all "as required" or PRN medicines \\
\hline & The prescription has an identifiable prescriber's signature (in ink) \\
\hline & Discontinued medicines are crossed off, dated and signed by a person with prescriber authority \\
\hline \multirow[t]{14}{*}{ Service User Experience } & Were you provided information about this service? \\
\hline & Were you introduced to the nurse or nurses responsible for your care? \\
\hline & Do you know the names of your nursing team? \\
\hline & Have you received information from your responsible nurse on how to manage symptoms of your illness? \\
\hline & Has your medication and any potential benefits/side effects been explained to you by your responsible nurse? \\
\hline & Have you got the relevant information on who to contact in times of a crisis? \\
\hline & Were you involved in developing your nursing care plan? \\
\hline & Were you offered a copy of your care plan? \\
\hline & Have you been offered the opportunity to have your family member/carer involved in your care? \\
\hline & Are you offered 1:1 nursing time as indicated in your care plan? \\
\hline & Has information been offered on organised activities/groups in your area? \\
\hline & Do the activities/groups offered support you in your recovery process? \\
\hline & Is there the opportunity for access to outside space? \\
\hline & Can you access fresh drinking water? \\
\hline
\end{tabular}

\section{Discussion}


It should be noted that metrics as applied to health care practices arise from the world of business where metrics were devised as means of setting targets and measuring attainment of these (Cusack, Dempsey Ryan, Kavanagh, \& Pitman, 2014). Pencheon (2008) suggests that within healthcare settings, metrics as measured by their indicators illustrate areas of practice performance and the degree to which expectations are being met. Hence, these can be used as a quality control measure in practice. Typically, metrics and their associated indicators are used to show benchmarking or attainment against agreed standards, with a view to ensuring and improving the quality of care (Gage, Heywood, \& Norton, 2012; Royal College of Nursing, 2012, 2009). It should be noted that while there are clear potential benefits to the implementation of metrics, there is ongoing concern that care processes, in this case the day to day business of mental health nursing cannot be adequately measured (Maben et al., 2012). The concern being that the interpersonal day to day activities delivered by mental health nurses are hard to measure and that mental health nurses do not work alone making their activities as distinct from multi-disciplinary team activities hard to isolate and quantity (Smith, 2012).

In this study, despite the lack of applicable evidence based metrics and indicators identified from the systematic review, the grey literature identified valuable starting points for the deliberations of the work-stream working group, in identifying areas of importance to mental health nursing in the Irish context. The literature sources that were identified ranged from full procedure guidelines with some underpinning evidence through to checklists of areas pertaining to practice to be measured.

Central to the conduct of this research and complimented by the rigorous research process outlined is the level of engagement with service user and family representatives and a broad cross-section of mental health nurses across grades, practice settings and geographical areas in Ireland. This ensured that mental health nursing QCMs and associated indicators arose from genuine consensus. Crucially there was service user and family representation from the outset, across the work stream working group deliberations through to the final Phase 4 consensus meeting, ensuring maximum possible involvement in the ongoing research. This approach reflects the policy emphasis in Ireland that mental health service provision should arise from genuine partnership between service users and service providers (Watts, Downes, \& Higgins, 2014; McDaid, 2013; Higgins, 2008).

The 9 metrics and 73 indicators included in the final suite show considerable synergy with research indicating areas where mental health nurses and service users have identified knowledge and skill deficits in the existing workforce (Bee et al 2008). By identifying prioritised areas where mental health nursing processes can be measured this research contributes to our understanding of what mental health nursing processes, they along with service users and carers representatives value. This understanding of these stakeholders' views on key areas of nursing process, indicates potential areas for the development of mental health nursing practice and education.

Despite the lack of applicable evidence identified from the systematic review every effort was made to ensure the quality of the mental health nursing metrics and indicators included in the final suite. The evaluation tool used identified four key attributes of metrics and indicators these being process focused, important, operational and feasible. The rigorous research design employing 4 Phases; systematic literature review, online Delphi survey of mental health nurses and consensus meeting with key stakeholders, means that the finally agreed metrics and indicators can be considered to be process focused with clear applicability mental health service users and mental health nurses in practice. Importantly, as noted in the systematic review section, not all of the agreed metrics and indicators have supporting clinical standards and an evidence base although they do have a strong practice evidence base. This understanding specifically impacts on feasibility, the fourth component of the judgement framework tool. This suggests that there is a need for robust piloting and evaluation of these metrics and indicators before rolling out service wide to identify potential unintended impacts and barriers (Campbell et al 2011). Consequently, this initial development of metrics and indicators should be followed by a rigorous baseline review of QCM uptake and implementation amongst mental health nurses as part of an ongoing evaluation

\section{Conclusion}

Achieving consensus on what mental health nurses do and how best to measures those processes in an important element of ongoing efforts to improve the safety and quality of mental health nursing practice. Having achieved its aim in producing a suite of mental health nursing metrics and indicators, there is now the opportunity to incorporate routine measurement into ongoing efforts to improve the quality of mental health nursing care. Any implementation of these metrics and indicators could provide valuable evidence of mental health nurses contribution to safe, quality, care processes.

\section{Declarations}

\section{Ethics approval and consent to participate}

This research was undertaken in accordance with required ethical guidelines and regulations. Accordingly approval for this study was granted by the Research Ethics Committee, National University of Ireland Galway on the 13th of December 2016 [Ref: 16-Dec-09, Mental Health Stream]. Informed consent was obtained from all participants. All participants had to indicate their explicit consent to participate by clicking on an 'I agree' button on the online participant information sheet before they could access each round of the Delphi. All potential consensus meeting participants were given a participant information leaflet and written consent to participate was obtained from each willing participant at the meeting.

\section{Consent for publication}

Not applicable

\section{Availability of data and materials}


The datasets used and/or analysed during the current study available from the corresponding author on reasonable request.

\section{Competing interests}

None

\section{Funding}

This project was funded by the Office of Nursing and Midwifery Services Directorate, Health Service Executive. The funder was involved, through membership of the steering group, identification of potential participants, study design, data collection, data analysis, and in completion of the manuscript.

\section{Authors' contributions}

$A H, N B, A G$, and $G C$ contributed to the design of the project. $A H, N B$ and $L M$ conducted the systematic review and the surveys. $A H, N B$, and $L M$ analysed the data. $A H$ and $L M$ drafted the manuscript. $A G, A B, M G$, and $G C$ contributed to the draft. All authors reviewed the final draft version of the manuscript prior to submission.

\section{Acknowledgements}

The authors are grateful to all the Mental Health Nurses in practice, NMPDU staff, work-stream Working-Group members, Directors of Mental Health Nursing, Practice Development Coordinators, who contributed to the collaborative development of this suite of quality care process metrics and indicators for mental health nursing practice in Ireland.

\section{References}

1. Bee P., Playle, J., Lovell, K., Barnes, P., Gray, R., \& Keeley, P. (2008). Service user views and expectations of UK-registered mental health nurses: A systematic review of empirical research. International Journal of Nursing Studies, 45(3), 442-457. https://doi.org/10.1016/j.ijnurstu.2007.02.008

2. Campbell, S.M., Kontopantelis, E., Hannon, K., Burke, M., Barber, A., \& Lester, H. (2011). 'Framework and indicator testing protocol for developing and piloting quality indicators for the UK quality and outcomes framework'. BMC Family Practice, 12(1), 85-95. https://doi.org/10.1186/1471-2296-12-85

3. Collins, P., Naughton, L., Heslin, R., \& Ryan, M. (2016). Advancing Recovery in Ireland. A Guidance Paper on Implementing Organisational and Cultural Change in Mental Health Services in Ireland. National Office for Advancing Recovery in Ireland. HSE: Mental Health Division. Dublin. http://hdl.handle.net/10147/613321

4. Cusack, E., Dempsey Ryan, D., Kavanagh, C., \& Pitman, S. (2014). An Evaluation of the Development and Implementation of a Nursing and Midwifery Metrics System in HSE Dublin North Healthcare Services, available: https://www.hse.ie/eng/about/who/onmsd/nmpdu/nmpddn/an-evaluation-ofimplementation-of-nursing-metrics.pdf Accessed: 13.12.2016

5. De Santis, M., Myrick, H., Lamis, D. A., Pelic, C. P., Rhue, C., \& York, J. (2015). Suicide-specific safety in the inpatient psychiatric unit. Issues in Mental Health Nursing, 36, 190-199.

6. Flenady, V., Wojcieszek, A.M., Fjeldheim, I., Friberg, I.K., Nankabirwa, V., Jani, J.V., Myhre, S., Middleton, P., Crowther, C., Ellwood, D., \& Tudehope, D. (2016). 'eRegistries: indicators for the WHO Essential Interventions for reproductive, maternal, newborn and child health'. BMC Pregnancy and Childbirth, 16(1), 293. doi: 10.1186/s12884-016-1049-y. Accessed: 12.10.2017

7. Gage, W., Heywood, S., \& Norton, C. (2012). Measuring quality in nursing and midwifery practice. Nursing Standard, 26(45), 35-40. doi: 10.7748/ns2012.07.26.45.35.c9208 Accessed: 16.03.2018.

8. Grabowski, D. C., Aschbrenner, K. A., Rome, V. F., \& Bartels, S. J. (2010). Review: Quality of Mental Health Care for Nursing Home Residents: A Literature Review. Medical Care Research and Review, 67(6), 627-656. doi: 10.1177/1077558710362538 Accessed: 16.03 .2018$.

9. Health Service Executive (HSE) (2012). A Vision for Psychiatric/Mental Health Nursing: A shared journey for mental health care in Ireland. Dublin: HSE.

https://www.hse.ie/eng/services/publications/nursingmidwifery\%20services/a\%20vision\%20for\%20psychiatric\%20mental\%20health\%20nursing.pdf

10. Health Service Executive (HSE) (2016). Advancing Recovery in Ireland. A guidance paper on implementing organizational and cultural change in mental health services in Ireland. Dublin: HSE. http://hdl.handle.net/10147/613321

11. Health Service Executive (HSE) Mental Health Division (2017a). Best Practice Guidance for Mental Health Services. Supporting you to meet Regulatory Requirements and towards Continuous Quality Improvement. Dublin: HSE. https://www.hse.ie/eng/services/list/4/mental-healthservices/mental-health-guidance/best-practice-guidance/documents/best-practice-guidance-for-mental-health-services.pdf

12. Health Service Executive (HSE) Mental Health Division (2017b). A National Framework for Recovery in Mental Health Services. A national framework for mental health service providers to support the delivery of a quality, person centred service. Dublin: HSE.

https://www.hse.ie/eng/services/list/4/mental-health-services/advancingrecoveryireland/national-framework-for-recovery-in-mental-health/recoveryframework.pdf

13. Health Service Executive (HSE) (2015). Guiding Framework for the Implementation of Nursing and Midwifery Quality Care-Metrics in the Health Service Executive Ireland. HSE. Dublin. 
14. Health Service Executive (HSE) (2014). Report of the Quality and Safety Clinical Governance Development Initiative: Sharing our learning. Dr Steevens' Hospital: Dublin.

15. Health Service Executive (HSE) (2015). Guiding Framework for the Implementation of Nursing and Midwifery Quality Care-Metrics in the Health Service Executive Ireland. HSE. Dublin.

16. Higgins, A. (2008) A Recovery Approach within the Irish Mental Health Services: A Framework for Development. Dublin: Mental Health Commission.

17. Kings Fund (2017) Quality improvement in mental health London: The King's Fund.

18. McCance, T., Telford, L., Wilson, J., Macleod, O., \& Dowd, A. (2012). Identifying key performance indicators for nursing and midwifery care using a consensus approach. Journal of Clinical Nursing, 21(7-8), 1145-54. doi: 10.1111/j.1365-2702.2011.03820.x.

19. McDaid, S. (2013). Recovery: What you should expect from a good quality mental health service. Dublin: Mental Health Reform.

20. Maben, J., Morrow, E., Ball, J., \& Robert, G., \& Griffiths, P. (2012). High Quality Care Metrics for Nursing. Kings College London. London.

21. Mental Health Commission (2016). Judgement Support Framework Version 3. Mental Health Commission: Dublin

22. Moher, D., Liberati, A., Tetzlaff, J., \& Altman, D. G. ( 2009). Preferred reporting items for systematic reviews and meta-analyses: The PRISMA statement. BMJ, 339, b2535. https://doi-org.libgate.library.nuigalway.ie/10.1186/2046-4053-4-1

23. O'Brien, A. Boddy, J. Derrylea, H, O'Brien, A (2004) Clinical indicators as measures of mental health nursing standards of practice in New Zealand International Journal of Mental Health Nursing 13, 78-88

24. Pencheon, D. (2008). The good indicators guide: understanding how to use and choose indicators. NHS Institute for Innovation and Improvement. available: https://www.england.nhs.uk/improvement-hub/wp-content/uploads/sites/44/2017/11/The-Good-Indicators-Guide.pdf Accessed: 16.03.2018

25. Royal College of Nursing (RCN)(2012) Nursing Dashboards- Measuring Quality, Publication no: 004 198, available: https://www.rcn.org.uk/professional-development/publications/pub-004198 Accessed: 16.03.2018

26. Royal College of Nursing (RCN)(2009) Measuring for quality in health and social care An RCN position statement, Publication no: 003 535, available: https://www.rcn.org.uk/professional-development/publications/pub-003535 Accessed: 19.02.2018

27. Schmitt, J., Langan, S., Stamm, T., \& Williams, H.C. (2012). Harmonizing Outcome Measurements in Eczema Delphi panel. Core outcome domains for controlled trials and clinical recordkeeping in eczema: international multiperspective Delphi consensus process. J Invest Dermatology, 131, 623-630.

28. Slemon A, Jenkins E, Bungay V. Safety in psychiatric inpatient care: The impact of risk management culture on mental health nursing practice. Nurs Inq. 2017;24:e12199. https://doi.org/10.1111/nin.12199

29. Skews, G., Meehan, T., Hunt, G., Hoot, S. \& Armitage, P. (2000). Development and validation of clinical indicators for mental health nursing practice. Australian and New Zealand Journal of Mental Health Nursing, 9, 11-18.

30. Smith, J.H.F. (2012). Has the alphabet changed? Revised quality assurance guidance for the NHSCSP. Cytopathology, 23, 39. available: http://onlinelibrary.wiley.com/doi/10.1111/cyt.12011/pdf

31. Tugwell, P., Boers, M., Brooks, P., Simon, L., Strand, V., \& Idzerda, L. (2007). OMERACT: an international initiative to improve outcome measurement in rheumatology. Trials, 8, 38. DOI: 10.1186/1745-6215-8-38

32. Williamson, R., Altman, D., Blazeby, J., Clarke, M., Devane, D., Gargon, E., \& Tugwell, P. (2012). Developing core outcome sets for clinical trials: issues to consider. Trials, 13, 132. https://doi.org/10.1186/1745-6215-13-132.

33. Yackel, E., McKennan, M., \& Fox-Deise, A. (2010). Nurse-Facilitated Depression Screening Program in an Army Primary Care Clinic: An Evidence-Based Project. Nursing Research, 59 (1), S58-S65. doi: 10.1097/NNR.0b013e3181c3cab6.

34. Watts, M., Downes, C. \& Higgins, A. (2014). Building Capacity in Mental Health Services to Support Recovery. An exploration of stakeholder perspectives pre and post intervention. Dublin: School of Nursing and Midwifery Trinity College Dublin.

\section{Figures}




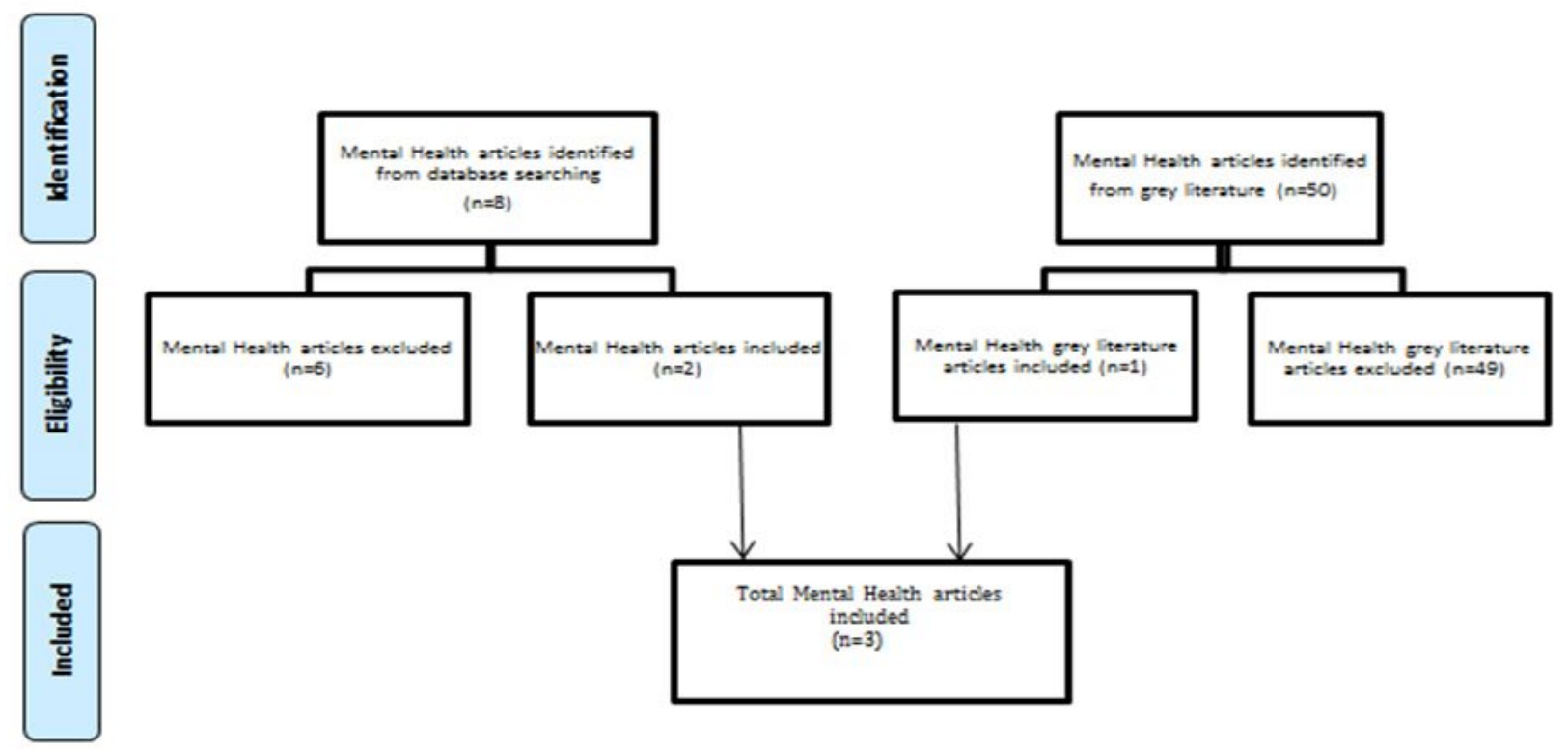

Adopted from: Moher D, Liberati A, Tetzlaff J, Altman DG, The PRISMA Group (2009). Preferred Reporting Items for Systematic Reviews and Meta-Analvses: The PRISMA Statement. PLoS Med 6(7): e1000097. doi:10.1371/journal.pmed1000097

For more information, visit www.prisma-statement.org.

일 (Ctrl) -

Figure 1

Search and selection flow diagram 